\title{
Chagas Disease across Contexts: Scientific Knowledge in a Globalized World
}

\author{
Luciano G. Levin, Pablo R. Kreimer \& Pablo Jensen
}

To cite this article: Luciano G. Levin, Pablo R. Kreimer \& Pablo Jensen (2021): Chagas Disease across Contexts: Scientific Knowledge in a Globalized World, Medical Anthropology, DOI: $\underline{10.1080 / 01459740.2021 .1946805}$

To link to this article: https://doi.org/10.1080/01459740.2021.1946805

\section{曲 Published online: 08 Jul 2021.}

Submit your article to this journal $\sqsubset$

Q View related articles $₫$

View Crossmark data $\asymp$ 


\title{
Chagas Disease across Contexts: Scientific Knowledge in a Globalized World
}

\author{
Luciano G. Levin (iD) ${ }^{a}$, Pablo R. Kreimer $\mathbb{D}^{b}$, and Pablo Jensen (iD) \\ aUniversidad Nacional de Río Negro, CITECDE, Río Negro, Argentina Consejo Nacional de Investigaciones Científicas y

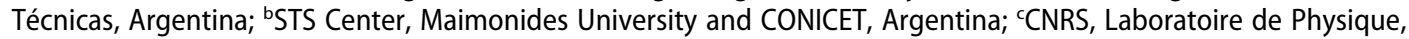 \\ Inst, Systèmes Complexes, Université de Lyon, ENS de Lyon, Lyon, France
}

\begin{abstract}
Chagas is the most important endemic disease in Latin America. It was progressively constructed as a relevant public issue, starting as a medical problem, focusing later on housing conditions, poverty, or vector agents. In recent decades, research has mainly focused on the parasite's biological characterization. In the meanwhile, both Chagas disease and knowledge about it spread out geographically. We analyze the worldwide scientific production on Chagas, showing that countries' research strategies depend on two main factors: endemicity and research traditions. This approach complements previous studies, allowing us to better understand the construction of Chagas disease as a social and scientific problem.

\section{RESUMEN}

Chagas es la enfermedad endémica más importante de América Latina. Se construyó progresivamente como una cuestión pública relevante, comenzando como un problema médico, centrándose después en las condiciones de vivienda, la pobreza o los agentes vectores. En las últimas décadas, la investigación se ha centrado principalmente en la caracterización biológica del parásito. Mientras, tanto la enfermedad de Chagas como el conocimiento sobre ella se han extendido geográficamente. Analizamos aquí la producción científica mundial sobre Chagas, mostrando que las estrategias de investigación de los países dependen de dos factores principales: la endemicidad y las tradiciones de investigación. Este enfoque complementa los estudios anteriores, permitiéndonos comprender mejor la construcción de la enfermedad de Chagas como problema social y científico.
\end{abstract}

\section{KEYWORDS}

Chagas disease; bibliometric; health; neglected diseases; knowledge use

Chagas is the most important endemic disease in Latin America, where over five million people are infected (Pérez-Molina and Molina 2018). Historically, it mainly affected a well-defined population: poor rural people. It was progressively constructed as a relevant public issue after Carlos Chagas identified a parasite in Brazil in 1908 that he named "Trypanosoma cruzi," in tribute to Oswaldo Cruz, founder of Brazilian modern microbiology (Kropf 2009). A short time later it was established that this parasite was the cause of a previously unknown disease, baptized with the name of his "discoverer."

However, the conception of Chagas disease as a public problem has changed throughout the $20^{\text {th }}$ century. It started as a medical problem that mainly affected rural populations, to focus later on other issues, such as housing conditions, poverty, the social inequalities of Latin American societies, or the

CONTACT Luciano G. Levin Ilevin@unrn.edu.ar E Universidad Nacional de Río Negro. CITECDE. CONICET. San Carlos de Bariloche, Argentina.

Media teaser: We analyze the worldwide scientific production on Chagas, the most important endemic disease in Latin America showing that countries' research strategies depend on two main factors: endemicity and research traditions. This approach complements previous studies, allowing us to better understand the construction of Chagas disease as a social and scientific problem. 
consideration of the vector agents of the disease (mainly Triatoma infestans). Recent approaches have emphasized the nature of the parasite and consequently the development of scientific knowledge about it, which became the basis for public interventions to fight the disease.

Social problems arise as processes of collective definition and thematization (Becker 1963; Blumer 1971; Conrad and Schneider 1980; Spector and Kitsuse 1977). However, very often scientific knowledge plays an important role to shape a given problem in a public arena; in this cases, scientific and public problems are co-constructed (Gusfield 1981; Hilgartner and Bosk 1988). Therefore, when a scientific problem transcends the boundaries of the academy and is translated in a public arena (and negotiated by several actors) into a public problem, we find a paradoxical situation: the scientific basis marks not only the origin of a public problem, but also the limits and the way it must be approached and, eventually, solved. This enables research, regulations, and institutions oriented to its resolution to emerge. A triumphalist rhetoric is usually installed, taking advantage of the existing social demand, where every initiative promises to solve the problem (or at least part of it). This hides the long and complicated process of transforming academic knowledge into useful artifacts. Indeed, this "knowledge transfer" is a traditional bottleneck in semi-peripheral contexts. In Latin America this key obstacle has been clearly identified from the 1960s on (Sábato and Botana 1970) and some authors characterized it as the AKNA obstacle: Applicable Knowledge Not Applied (Kreimer and Thomas 2006). However, very often the knowledge produced is not used locally but in a developed country. This has been perceived as "blind technology transfer" (Codner et al. 2012) or 'cognitive expropriation" (Kreimer and Zukerfeld 2014).

Therefore, we consider Chagas disease as a social, scientific, and a public problem. In fact, for long decades, it has been labeled as a "tropical disease" in reference to its geographical distribution, a "neglected disease" meaning the lack of interest in its resolution through pharmacological initiatives, weak government policies and stigmatization as a "disease of poor rural people." However, although in a good part of the discourses these representations are still very present (WHO 2020), Chagas disease does not fit well today inside those categories, since (i) its geographic scope has extended to other "non-tropical" regions, (ii) various enterprises mainly associated with nonprofit organizations or government initiatives are developing drugs, diagnosis kits, and other initiatives to fight it, which makes this disease relatively less "neglected" than it was in the past, and (iii) in many countries, the affected population, although still poor, is no longer mostly located in rural areas.

Qualitative approaches from the sociology and history of medicine (Kropf 2009; Zabala 2010) have characterized the development of Chagas disease, and the knowledge produced, in several periods, particularly in Argentina and Brazil. In the early twentieth century, knowledge production was focused on clinical research, with a strong microbiological basis. Progress was made on the systematization of the disease, its symptoms and on its definition as a relevant health issue. During the second period between 1940 and 1960 - several public interventions strategies such as "house improvements," or pesticides were designed. In the late 1970s, biochemistry and immunology, and later molecular biology, provided new knowledge and redefined the disease, securing its inclusion in internationally academic circles (Kreimer 2015). In Latin American countries, public health policies focused on vector control, but these strategies lost relative weight, while the production of knowledge from molecular biology increased, particularly from the 1980s onwards.

The abovementioned historical and sociological studies have proposed explanations to account for the lack of connection between the production of knowledge on Chagas disease and the social and economic use of such knowledge for prevention and treatments. In particular, it was noted that large pharmaceutical laboratories lacked interest because the people affected by Chagas disease are from particularly poor rural areas. It has also been suggested that $T$. cruzi is an attractive research model for international science (Kreimer 2015, 2019) because it shares features with other Trypanosomatidae that cause other diseases, such as sleeping sickness caused by T. brucei in Africa (Kennedy 2013), and Leishmaniasis (Aslett et al. 2009) in Africa, America and Europe (Suárez et al. 2012). 
Until now, most existing literature has analyzed Chagas disease as a "Latin American" disease and has therefore considered only the knowledge produced in this region. However, research has also been carried out in other countries, due to the interest of several worldwide scientific groups, or, probably more important, because of the spread of Chagas beyond Latin American countries. Indeed, Chagas has gone from being "a Latin American health problem to [...] a world health problem" (Schmunis and Yadon 2010: 1). Bern et al. (2019) identified 11 species, other than Triatoma infestans, the vector insect of the disease, in the southern states of the US where at least 300,000 people are estimated to be infected. According to Strasen et al. (2014) there are Chagas infected people in most European Union countries, through transmission by various routes (blood transfusion, mother to child). Unsurprisingly, a higher incidence is found in Spain, Italy, and Portugal where Latin American migrants concentrate, but there are also a growing number of cases in Switzerland, Sweden, and the Netherlands.

We propose in this article to identify the historical evolution of the production of knowledge on Chagas disease. We stress the diversity of studies, in the crossroads of epistemic objects and scientific specialties. The objects range from the parasite (T. cruzi) up to the population of vectors, passing through the clinical manifestations, research on treatments and drugs, as well as epidemiological studies.

The theoretical assumption of our work is that in every form of construction of a public problem, in particular health problems (Epstein 1996) there is one or more underlying knowledge, which at the same time proposes the basis on which the problem is formulated, the way actors are involved, and the forms of public intervention (Gusfield 1981; Kreimer 2019).

The study of this vast production of scientific knowledge about Chagas has been partially addressed, particularly focusing on characterizing historical stages of this disease and the knowledge produced during each period. Thus, we identified various stages of research on Chagas in Argentina (Kreimer and Zabala 2007), as well as the relationship between the production and use of knowledge, taking Chagas as a sociological model for the study of such processes in semi-peripheral contexts (Kreimer 2019). Kropf (2009) has published a complete history of scientific and medical research on Chagas in Brazil, while Zabala (2010) carried out an analogous work in Argentina.

\section{Methodology}

Unlike existing qualitative studies of this disease (Briceño-León 1990; Kropf 2009; Zabala 2010), or a scientometric study focused on Chagas cardiomyopathy (González-Alcaide et al. 2018), we consider the total production of knowledge on Chagas registered in the Web of Science (WoS). In this way, we will identify epistemic communities and observe the thematic and geographical distribution of knowledge production and the degree of intensity of each of the issues that are part of the global agenda.

But to understand Chagas as a social, scientific, and public problem not only disciplines or specialties are relevant. There are also technical conditions (e.g. DNA sequencing), the positions of disciplines in a specific field at a historical moment (e.g. genetics in molecular biology at the end of the twentieth century), social and political issues (e.g. migrations), health issues (the relationship between Chagas and pregnancy), among others. This is why we complemented our study with an historical and sociological analysis using interviews as sources that could lead us to understand how research on Chagas disease has evolved and spread around the world in this multi-level framework.

\section{Article selection}

We used the following search strategy to obtain articles' metadata from WoS: “TS = Benzinidazol or TS $=$ Benznidazol or TS $=$ Nifurtimox OR TS $=$ Cruzi $^{\star}$ OR TS $=$ chagas OR TS $=$ tripanosoma cruzi OR TS = trypanosoma cruzi OR TS $=$ t. Cruzi." It was executed on April 01, 2019 and it brought up 24,178 articles published from 1921 through April 01, 2019. 


\section{Clustering, interpretation, and labeling}

Documents were processed using the bibliographic coupling approach (Kessler 1963) which groups articles according to the similarity of their references. The hypothesis underlying this technique is that texts sharing more references are closer in epistemic space. We used the software "BiblioTools" (Grauwin and Jensen 2011) to create clusters linking articles that share three or more references. Note that clustering by shared references filters out irrelevant records brought up by the search strategy, as these are not connected (through common references) to the records that represent the core of our query. We end up with 19,403 articles distributed among 14 clusters (containing one hundred or more documents), each article belonging to a single cluster.

To understand the scientific meaning of the clusters, we extracted the metadata associated with each article: authors, institutions, countries, keywords, thematic fields, journals of publication, references, referenced journals and words present in titles. Detailed information about clusters is available online (http://rid.unrn.edu.ar/handle/20.500.12049/7238)

To summarize the information and label the clusters, we used the highest frequencies of appearance and $\sigma$ values. A short example can help understand this point: The 4th cluster "VecTRO" has, among its top 10 keywords, the words "Reduviidae," "Transmission," "Hemiptera," and "Vector(s)," all referring to the vector (insect) of the disease. In addition, "Reduviidae" (the second keyword by percentage) has a $\sigma$ of 47.83 while "Tripanosoma Cruzi" has a $\sigma$ of -10.85 . This means that Reduviidae is the most specific (and relevant) keyword, confirming that articles in the cluster deal with the vectors rather than with the parasite or other organisms involved in the disease. For all clusters, we supplemented this information by reading in full the most relevant referenced articles.

\section{Interviews with specialists}

We held three rounds of meetings with six specialists in core disciplines in Chagas disease research. In addition, we interviewed specialists in different areas of Chagas research, who provided their interpretations of the clusters. We interviewed a social scientist specialized in neglected diseases; a biotechnologist specialized in molecular biology and protein description; a biologist specialized in DNA sequencing; a biologist specialized in parasitology and a pharmacologist specialized in drug search research. At each meeting we conducted a brief general interview to set up the subject and create confidence regarding the level of information that we were managing (a critical point, since many senior researchers mistrust anyone outside their field of expertise). Then we showed the data, along with a brief explanation of the methodology. We asked the specialists to provide their own interpretations of the clusters, without giving them any previous interpretation to avoid influencing them. Once they had provided their interpretations, we compared them to the previous interpretations, in a process that gave rise to interesting exchanges and greatly enhanced this study. Finally, we sent all specialists the final versions of the interpretations to prevent any involuntary errors or any additional content from slipping into the clusters. Once a given cluster had been interpreted, we defined a "label" to describe it. Labels usually consisted of joining a relevant keyword and the most representative discipline in the cluster.

\section{Characterization of countries}

We calculated the proportion of articles per country in each cluster, to provide a measure of the relative effort made by each country in a subfield, following the method presented in detail in Levin et al. (2016). Note that articles are attributed to a country regardless of the number of authors belonging to one of its institutions, i.e. an article authored by five researchers in Switzerland, one in Italy, and two in the US is attributed equally to the three countries. Normalization according to relevant "worldwide effort" provides the RCA Index (Balassa 1965). Finally, we applied Principal Component Analysis (PCA) using the FactoMineR package (Le et al. 2008) to find the most significant 
Table 1. General data on Chagas' knowledge production.

\begin{tabular}{|c|c|c|c|c|c|c|}
\hline & \multirow[b]{2}{*}{ Country } & \multicolumn{4}{|c|}{ Articles } & \multirow{2}{*}{$\begin{array}{l}\text { People } \\
\text { Endemic } \\
\text { Chagas }\end{array}$} \\
\hline & & $\begin{array}{c}\text { Total articles on } \\
\text { WoS for the study } \\
\text { period }\end{array}$ & $\begin{array}{c}\text { Number of Chagas } \\
\text { articles on WoS for the } \\
\text { study period }\end{array}$ & $\begin{array}{l}\text { Contribution to } \\
\text { world research on } \\
\text { Chagas }(\%)\end{array}$ & $\begin{array}{l}\text { Total Chagas } \\
\text { production/ } \\
\text { country }(\%)\end{array}$ & \\
\hline 1 & Brazil & 834,082 & 8,080 & 33.4 & 0.97 & Yes \\
\hline 2 & USA & $16,098,877$ & 5,643 & 23.3 & 0.04 & No \\
\hline 3 & Argentina & 228,846 & 3,108 & 12.9 & 1.36 & Yes \\
\hline 4 & United Kingdom & $4,388,252$ & 1,532 & 6.3 & 0.03 & No \\
\hline 5 & France & $2,558,866$ & 1,265 & 5.2 & 0.05 & No \\
\hline 6 & Spain & $1,344,261$ & 1,362 & 5.6 & 0.10 & No \\
\hline 7 & Venezuela & 42,831 & 758 & 3.1 & 1.77 & Yes \\
\hline 8 & México & 293,386 & 825 & 3.4 & 0.28 & Yes \\
\hline 9 & Germany & $3,004,281$ & 758 & 3.1 & 0.03 & No \\
\hline 10 & Chile & 147,417 & 613 & 2.5 & 0.42 & Yes \\
\hline
\end{tabular}

correlations between countries' efforts. To interpret the PCA results, we added variables for socioeconomic, scientific, and epidemiological characterization of the countries, such as GDP, scientific growth rate, presence of autochtonous Chagas disease or participation in large international projects for Chagas research. These additional variables are not used to compute the principal axes, but they help to understand the data.

\section{Dynamics}

Finally, we analyzed the data over time, considering time "windows" and observing the associations among them. This provided a picture of what happened with the research topics over time.

\section{General data about research on Chagas disease in the world}

A general analysis of the distribution of research on Chagas worldwide (measured in number of WoS articles) shows that out of the top ten countries (over 500 articles), six of them are from the Americas (US, Brazil, Argentina, Venezuela, Mexico, and Chile), where the disease exists naturally, while the other four are European countries, three of which have a robust biomedical and pharmaceutical tradition (UK, France, Germany) (Table 1).

With the exception of Venezuela, the five Latin American countries correspond to those with greater scientific development in general, measured in terms of production, number of researchers, and sponsors in international scientific cooperation (Kreimer and Levin 2013). ${ }^{1}$ They are also countries with high percentages of infected populations (0.6\% to 3.64\%) (Buscaglia, Kissinger and Aguero 2015). ${ }^{2}$

The apparently high participation of the US and European countries raises new questions. What variables explain the presence of non-Chagas-endemic countries? What are the historical dynamics of participation of non-Chagas-endemic countries?

\section{Predominant themes in Chagas research}

The bibliographic coupling approach (Kessler 1963) reveals 14 main Chagas clusters. Since the timespan analyzed is long, the references in some clusters may correspond to very different periods. Table 2 provides general information on all clusters and includes average year of publication for the articles in each cluster (AYP).

These clusters allow us to describe the main sub-fields into which Chagas research has been divided. Following Cambrosio and Keating (1983), we consider each subfield to be made up of multiple disciplines that fight within the field to impose their vision, and the disciplinary stake. This description 
Table 2. Principal topic clusters.

\begin{tabular}{lcclll}
\hline ID & Number of articles & $\%$ & \multicolumn{1}{c}{ Label } & & \multicolumn{1}{c}{ Topic } \\
\hline 8 & 3,008 & 15.5 & CardioCAR & Clinical and drug studies in chronic phase. & 2011 \\
4 & 2,855 & 14.7 & IFN-IMM & Studies of in vitro and in vivo infections of $T$. cruzi and immune responses. & 2006 \\
3 & 2,110 & 10.9 & AbodyPAR & Functional description of parasite surface. & 1986 \\
5 & 2,012 & 10.4 & VectorTRO & Entomology and population studies of several vectors. & 2007 \\
1 & 1,695 & 8.7 & DrugsBIOCHEM & Drug Search. Nitrofurans. Biochemistry. & 2005 \\
7 & 1,658 & 8.5 & GenBMOL & Genomics of $T$. cruzi. & 2007 \\
10 & 1,299 & 6.7 & TryStrainPAR & Studies onT. cruzi molecular variability. & 2005 \\
6 & 1,244 & 6.4 & TrypBMOL & Biomolecular description of $T$. cruzi and life cycle. & 2004 \\
12 & 1,004 & 5.2 & KetoBIOCHEM & Studies in vivo and in vitro of $T$. cruzi inhibitors. & 2007 \\
2 & 835 & 4.3 & ProtBMOL & Protein structure and expression. Search for targets for treatments. & 2004 \\
9 & 772 & 4.0 & BloodHEM & Studies on $T$. cruzi in blood and transfusion problems. & 2002 \\
11 & 500 & 2.6 & VectPAR & Studies of host and vector and dynamics of the parasite between them. & 2008 \\
15 & 227 & 1.2 & DigeGASTRO & Achalasia caused by $T$. cruzi. & 1999 \\
14 & 184 & 0.9 & PlantPHA & Search for natural product with antiparasitic activity. & 2010 \\
\hline
\end{tabular}

of science structure differs noticeably from the information drawn directly from WoS categories (Levin et al. 2016). ${ }^{3}$ This shows that WoS broad subject categories are inadequate for interpreting our results because their construction reflects a more disciplinary structure while our clusters shows us which disciplinary part of the cluster prevails and allow us to build more accurate labels.

We also studied the diachronic dynamics of these clusters. Figure 1 shows the development of the clusters as they unfold over time from the 1970s to the present.

The cluster with the largest number of articles (CardioCAR, 3008 art. [15.5\%]) corresponds to clinical trials and drugs in the chronic phase of the disease, principally regarding its cardiac effects (Subject "Cardiac \& Cardiovascular Systems": 14.86\%, $\sigma=26.4$; Keyword “Cardiomyopathy": 8.64\%, $\sigma=26.4)$.

As one of the interviewed biologists pointed out:

There is a common thing here ... from my point of view, from the discipline, obviously, why not, because ... it starts from the same problem that is "chronic Chagas disease," with "heart disease," with "cardiomyopathy," which is the big question of how to solve this issue and if the treatment, let's say, makes sense to be given to people who have chronic disease with cardiac symptoms, because what was shown in some works with some of these "trials" is that ... uh ... even though you treat them, if they have already entered the heart problem, no ... it stops, it does not reverse, as the disease continues to evolve. And that's one of the big questions they asked themselves, what is the endpoint, what is the ... what are you going to measure as success in a clinical trial of treatment. (Biologist 1, 2019)

This research was performed mainly in Brazil, Argentina, and Spain, with AYP $=2012$. Two reasons account for the large total number of articles and recent increase in this cluster. Firstly, in the late 1980s there was a change in paradigm regarding the chronic phase of the disease, because it was formerly believed that once a patient was infected, disease progression was related to autoimmune aspects. However, the use of more advanced PCR techniques such as qPCR (Marti et al. 2008; Schijman et al. 2011), showed that the parasite was still present in the human body long after the original infection. This changed the way in which intervention on the disease was sought, because antiparasitic strategies became relevant in the chronic phase and changed the dynamic of the cluster in the 1990s. Secondly, new techniques enabled more effective diagnosis, and in conjunction with the migratory processes of Latin American parasite carrier populations to Europe and the US in recent decades, these techniques drove research on diagnosis and promoted the publication of studies on chronic treatment of Chagas in other countries like Spain or Switzerland. Some of the interviewed specialists pointed us in this direction:

[on cluster dynamics] ... because of the paradigm shift that occurred with respect to how it is done, what is the theory of what the pathological process is, let's say. At one time it was thought, until the eighties, that it was an autoimmune issue. That the parasite entered, did something that stayed there sleeping, let's say, and then an autoimmune process was the one that generated ... because the parasite was never found [...] Then it was 


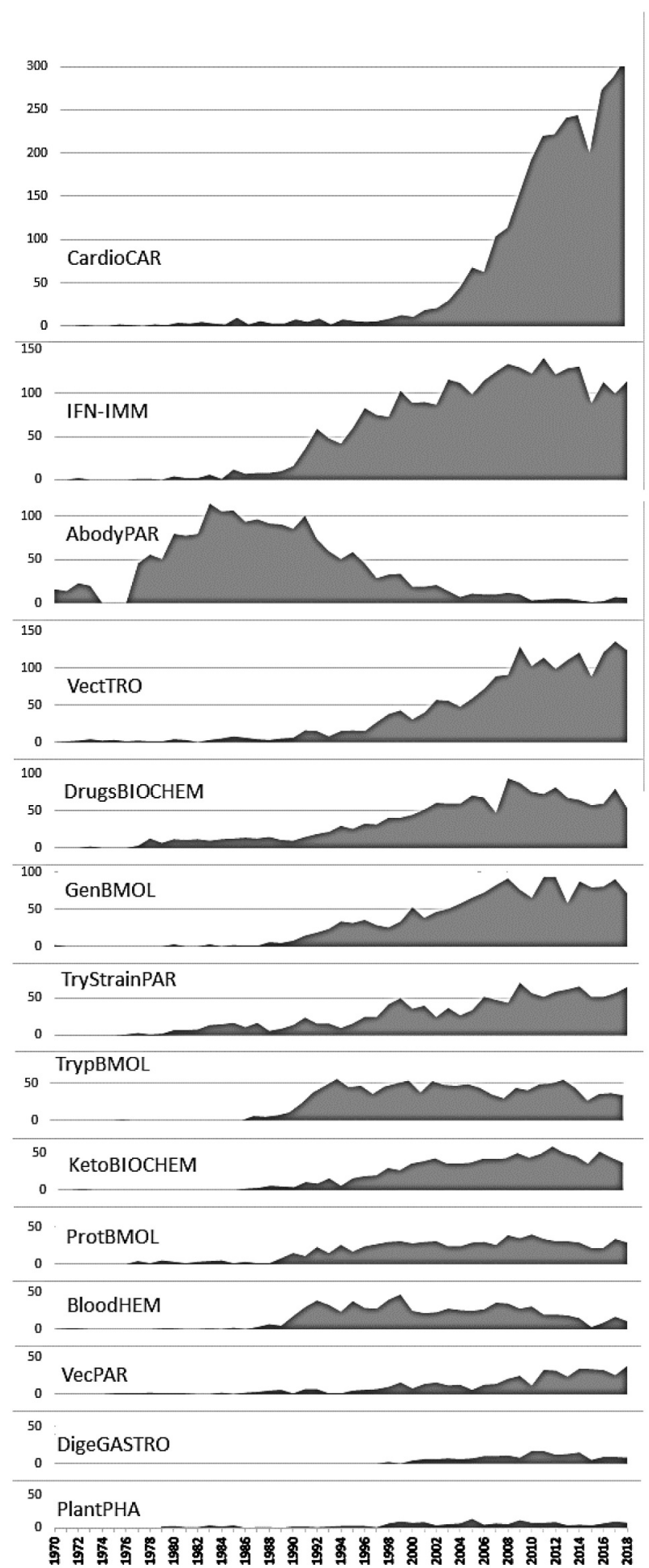

Figure 1. Dynamics over time of the main clusters. 
discovered with more sensitive techniques such as PCR [...] presence of DNA of the parasite in the heart, in the target organs, in the blood, like ... the parasite always has to be persistent in the individual to cause the disease, that is, it is not only autoimmune, but it is an infectious disease. (Biologist 2, 2019)

The $2^{\text {nd }}$ largest cluster (IFN-IMM, 2855 art. [14.7\%]) contains in vitro studies on the T. cruzi immune response. The countries most involved in this research are Brazil and the US, with AYP 2006. These in vitro immunological studies seek to describe the disease mechanism at biochemical level. This research line was very important during the past decade, but seems to be in a stable phase as these immunological techniques are no longer a scientific novelty. Biologist 1 saw immediately this when he saw the metadata:

it seems to be a lot of immunological information here. In vitro too ... with several authors that are no longer in the top of the knowledge production ... (Biologist 1, 2019)

The $3^{\text {rd }}$ largest cluster (AbodyPAR, 2110 arts. [10.9\%]) is the oldest cluster (AYP = 1986). It addresses the functional description and structure of T. cruzi, mainly surface glycoproteins involved in recognizing and infecting hosts. This topic was important in the identification of targets for pharmacological intervention. These studies were conducted mainly in Brazil, Argentina and the US. The dynamics of this cluster is unique: it started from the very beginning of research on Chagas disease, with major growth in the 1980s - associated with the rise in the development of T. cruzi molecular biology - and a peak in the early 90s. After that, however, knowledge production fell off abruptly as most of the information about the parasite at functional level was by then available.

The $4^{\text {th }}$ cluster is VecTRO (2012 arts. [10.4\%]), with AYP 2007. It groups entomological studies on populations of the vectors (insects), in particular Triatoma infestans. These are studies from Brazil, Argentina and also Mexico, which appears for the first time, with more than $10 \%$ of the articles in one cluster. These studies focus on surveillance of the insect vector (Triatoma infestans), description of diversity and evolution of insects and the effect of insecticides used to control them. It is a very old cluster, dating back to the very origin of Chagas research, but which has been growing steadily. Increasing interest is explained by (a) the inception and widespread use of satellite methods for studying insect populations, which generated new, more precise knowledge and renewed interest in the subject (Ceccarelli et al. 2015; Gorla 2002; Hay et al. 2006), and (b) the increase in vector distribution as a result of climate change (Cerda et al. 2008), which makes it relevant to study new regions. The dynamics of this line of work is explained by the increasing importance assigned to Chagas disease in the US as a result of migrations both of people (Kjos et al. 2008; Sarkar et al. 2010) and insects as a result of climate change (Sarkar et al. 2010; Waleckx et al. 2014). Both facts are reflected in this cluster by the high participation of the US as well as the presence of Mexico, unusually represented in this line. In this regard, the CDC reports that since 2008, there has been increasing interest in US states regarding epidemiologic surveillance of the disease. In 2008, only two US States were addressing the issue: Arizona, because of its proximity to Mexico, and Massachusetts, due to Latino immigration. At present, systematic studies are being conducted in more than eight States (Bennett et al. 2018).

The $5^{\text {th }}$ cluster (DrugsBIOCHEM, 1695 arts [8.7\%]) groups texts about basic research in search of drugs (pharmacology) with antiparasitic effects using biological/chemical approaches (in contrast with molecular and biochemical approaches). These articles were published mainly in Brazil, the US, UK, Argentina, Uruguay, and also Spain and Chile. One of the pharmacologists we interviewed gave us key information to understand this cluster:

With Spain, having done the $\mathrm{PhD}$ there, on issues that had nothing to do with, we maintained a relationship with our group of origin and in turn, we went to other groups more related with calculus and others, in turn, with postdoctoral activities in Madrid - we did the doctorate in Pamplona, then Madrid, Pamplona itself another different group, there were three groups with which direct contact was established, then the concept of Trypanosoma cruzi or Chagas was incorporated into those groups. Now those groups work on Chagas because of us. It was very well seen to engage in a neglected third world disease. In addition, many proposals arise from 
Glaxo, GSK, which propose platforms - or the DNDi itself - to find new drugs, it was an important new economic vein. When you work on that -development of new drugs- it is the same to work on cancer or on T. cruzi.

With the group from Chile, one of them appears down there, there is the Malla group and the Morelho group, it was one of the Chilean academics we worked with. We did a whole series of EPR studies, Nuclear Magnetic Resonance ... [...] and then we had models in the amastigosta form. It had more collaboration with Chile than with Argentina. (Pharmacologist, 2020)

Many of these studies are associated with clinical trials propelled by the (Drugs for Neglected Diseases Initiative) DNDi, in which Spain, in recent years, plays a major part based on studies at hospitals in Barcelona and Madrid (Munoz et al. 2009). Here we could find also articles focusing on the surveillance of Chagas prevalence in non-endemic countries (Requena-Méndez et al. 2015). The increase in Latin American immigration, particularly Bolivian immigrants to Spain - among whom the prevalence of Chagas disease has been reported to be higher than $18 \%$ (Requena-Méndez et al. 2015) - explains the recent high level of interest in the subject in Spain and other non-Chagas-endemic countries in clinical studies and drug development (Gascon et al. 2010).

The $6^{\text {th }}$ cluster (GenBMOL, 1658 arts. [8.5\%]) consists of articles on the genomic description and molecular biology of trypanosomatids. This line of study gathers articles from the 80s and early 90s that gave rise to the T. cruzi genome projects (Zingales et al. 1997) and other tripanosomatidae parasites, like T. brucei and T. leishmania. Its growth from the year 2000 is explained by the fact that this was the time when the most important genome results were achieved. With the inception of bioinformatics, this line became even more important, and is still active today (Ferpozzi and Levin 2014).

The $7^{\text {th }}$ cluster (TryStrainPAR, 1299 arts. [6.7\%]) consists of studies on parasite diversity at a molecular level and the underlying epidemiology. They depend mainly on the inception of PCR techniques and their successive improvements, which have maintained interest and broadened their usefulness. We have mentioned above how the inception of qPCR enabled more precise diagnoses (Abras et al. 2018), modifying important conceptions regarding the chronic phase of the disease. Notwithstanding, the dynamics are similar to those for line 4 , because even though the techniques are valuable, they are not a novelty and no great progress is expected from them alone.

The $8^{\text {th }}$ cluster (TrypBMOL, 1244 arts. [6.4\%]) consists of articles on cell invasion mechanisms by which the parasite infects mammal cells. These are peripheral studies with relation to Chagas, but contribute somewhat useful information for understanding the context of the disease and providing better guidance for treatments.

The 9th cluster (KetoBIOCHEM, 1004 arts, APY = 2007) is about in-vitro studies of several inhibitors and other intracellular conditions of growth and expression of T. Cruzi, like Ketoconazole, an antimicotic drug studied for Chagas and Leishmaniasis (caused by T. leishmania).

The $10^{\text {th }}$ cluster (ProtBMOL, 835 arts. [4.3\%]) is highly specific, addressing chemotherapies and biological chemistry in the study and evaluation of mechanisms and drugs for the treatment of Chagas disease in the laboratory. It addresses parasite evasion mechanisms.

There are four additional clusters. They include hematological and transfusion studies (BloodHEM, 772 arts.); studies on the dynamics of the parasite between host and vector (VectPAR, 500 arts.); digestive diseases (Achalasia) associated with Chagas (DigeGASTRO, 227 arts) and a very small and recent cluster (PlantPHA, 184 arts., AYP $=2010$ ) focusing on the search for natural products with antiparasitic activity, in which the only Chagas-endemic participating country is Brazil.

\section{Understanding the complexity of Chagas research}

One important aspect of this scientometric analysis is to reveal, through the diversity of the 14 clusters, the complexity of "Chagas disease" as a research object. The 14 topics involve a broader spectrum, longer time scale and participation of more countries than had been described to date in the aforementioned qualitative studies. For example, some disciplines - such as pharmaceutical research - 
are found to have a degree of development which had not previously been noted, as well as development in contexts that had not been taken into account, such as the US or Switzerland.

With our analysis we can see how disciplines (e.g. Parasitology), fields (e.g. Triatominae studies) and sub-fields (e.g. Molecular Biology of T. cruzi) are related in order to build Chagas as a broader problem. The research on Chagas disease has evolved from four broad topics (Figure 2): a) parasites, evolving from the oldest studies on antibodies and proteins toward a diversification in current studies on parasite molecular biology, metabolism, proteins, and genome; b) the search for drugs, both natural and synthetic; c) human hosts (patients), evolving toward the study of associated cardiac diseases (cardiomyopathies), immunological studies and studies on diagnosis in humans, and d) vectors, consolidated in a research line welldistinguished from the rest and with few links to other research lines. The 14 clusters derive from these four major ways to look at the problem. Surprisingly, the recent literature (Bern et al. 2019) points out that the main achievements in Chagas disease control were through vector control programs, but our study indicates that the knowledge production in this area is less intense. The temporal evolution of clusters reveals the relative interest of the research community. Thus, while the study of the vector has remained

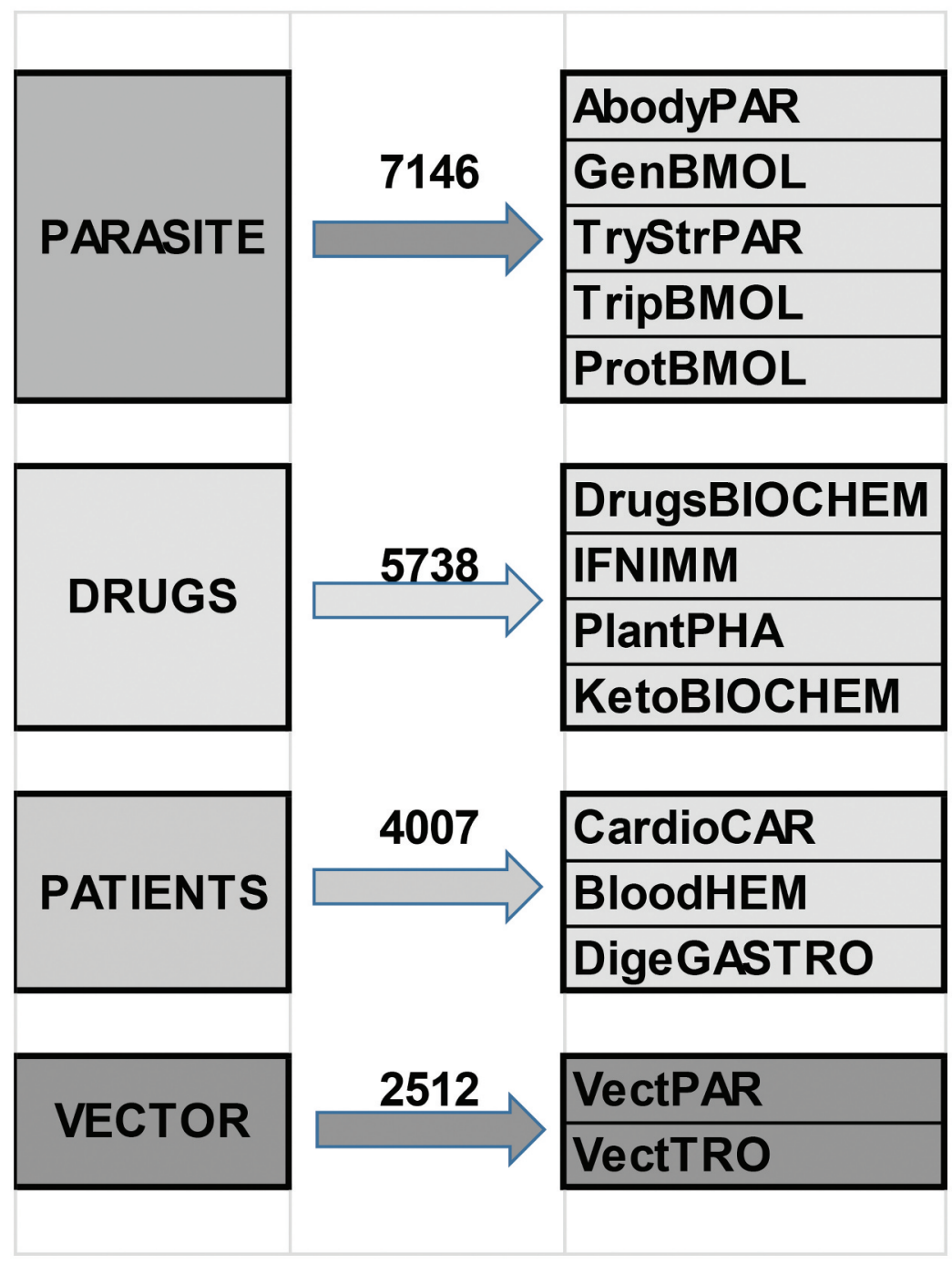

Figure 2. Topics, number of articles and clusters in Chagas disease research. 
consistently organized in two clusters (but only one, VecTRO, represents $80 \%$ of this topic, the study of patients is represented by three clusters with a huge prevalence of CardioCAR (75\%), pointing out the clinical character of this topic). The study of drugs is tackled in four clusters: the two biggest clusters are related to very basic and classic research (IFN-IMM and DrugsBIOCHEM), while the two smallest to seeking new drugs and studies of current treatments. Finally, the parasite itself has been the focus of the greatest interest, with five clusters and the major number of articles, in line with the previous interpretation in which Trypanosoma cruzi is interesting because it shares features with other parasites and is used as a "model organism."

\section{International distribution of Chagas research}

Our study also allows us to investigate in detail the relative contribution of different countries. Three countries are world leaders, as they are present in nearly all the clusters: Brazil, the US, and Argentina. Spain, France, and the UK are very important too, though they focus on fewer topics. To better understand the international distribution of Chagas research, we carried out a PCA analysis on the RCA Indexes. The two main dimensions explain respectively $36 \%$ and $17 \%$ of the data variability (Figure 3 ).

Interpretation of the axis points out that the first axis contrasts countries conducting biomedical research with biomolecular orientations in the laboratory (clusters GenBMOL, ProtBMOL, TrypBMOL) with Chagas-endemic countries where research focuses on more pressing issues, such as cardiology, epidemiological and diagnostic studies, field research, and patients (CardioCAR, BloodHEM), as well as entomological studies to describe and ultimately control the vectors (VecTRO, TryStrainPAR). This contrast can be related to a difference in wealth: rich countries spending a significant fraction of their wealth on science on the right, poor countries on the left. Nearly all the subjects on the left side are "applied" and pharma-oriented to natural or plant-derived products (without much chemical or molecular synthesis, PlantPHA), whereas those on the right include more basic research and more advanced strategies in the search for drugs at Immunological level (SuprIMM, IFN-IMM). There are more Chagas-endemic countries (on the left, Bolivia, Paraguay, Colombia, Peru, Mexico) than non-Chagas-endemic countries (on the right, EU, Asia). The exceptions are Argentina and Brazil, because they have a relatively higher degree of development and greater weight in biomedical research. Thus, close to the center we find countries of intermediate development, with high incidence of the disease, and major development of research on Chagas, in particular Argentina and Brazil, and to a lesser extent, Venezuela and Chile.

The second axis reveals the applied aspects of research. Toward the top we find the descriptive articles (VecPAR, TrystrainPAR) and articles on epidemiological surveillance, whether of patients (BloodHEM), or insects (VecTRO), while toward the bottom there are clearly clusters about patients' treatment (CardioCAR, PlantPHA and DrugsBIOCHEM). It is interesting to note that the oldest clusters are at the top right, where countries with strong traditions of Chagas research (Brazil, Argentina) together with the more highly developed countries are located (except Spain and Switzerland). The newer clusters are below, associated with Spain, Switzerland, and Uruguay, countries that were involved in Chagas research through new demands on knowledge associated with migrations, both of scientists and infected people.

I'm talking about the year 92, before that, Uruguay had nothing, then it was a group of theoretical chemists [...] then I went to do my PhD to work in [...] something else [...] I did it in Spain [...] and when I came back already in $94-95$, the country had already changed, there was a greater capacity to get into the R\&D of new drugs and it seemed to us that Chagas was a line that had been left unfinished from the point of view of drug development [...] I presented the first project, the CONACyT goalkeeper told me “Isn't this disease already cured?" No, it was never relevant. For Uruguay it was not relevant but it was for Latin America. (Pharmacologist, 2020) 

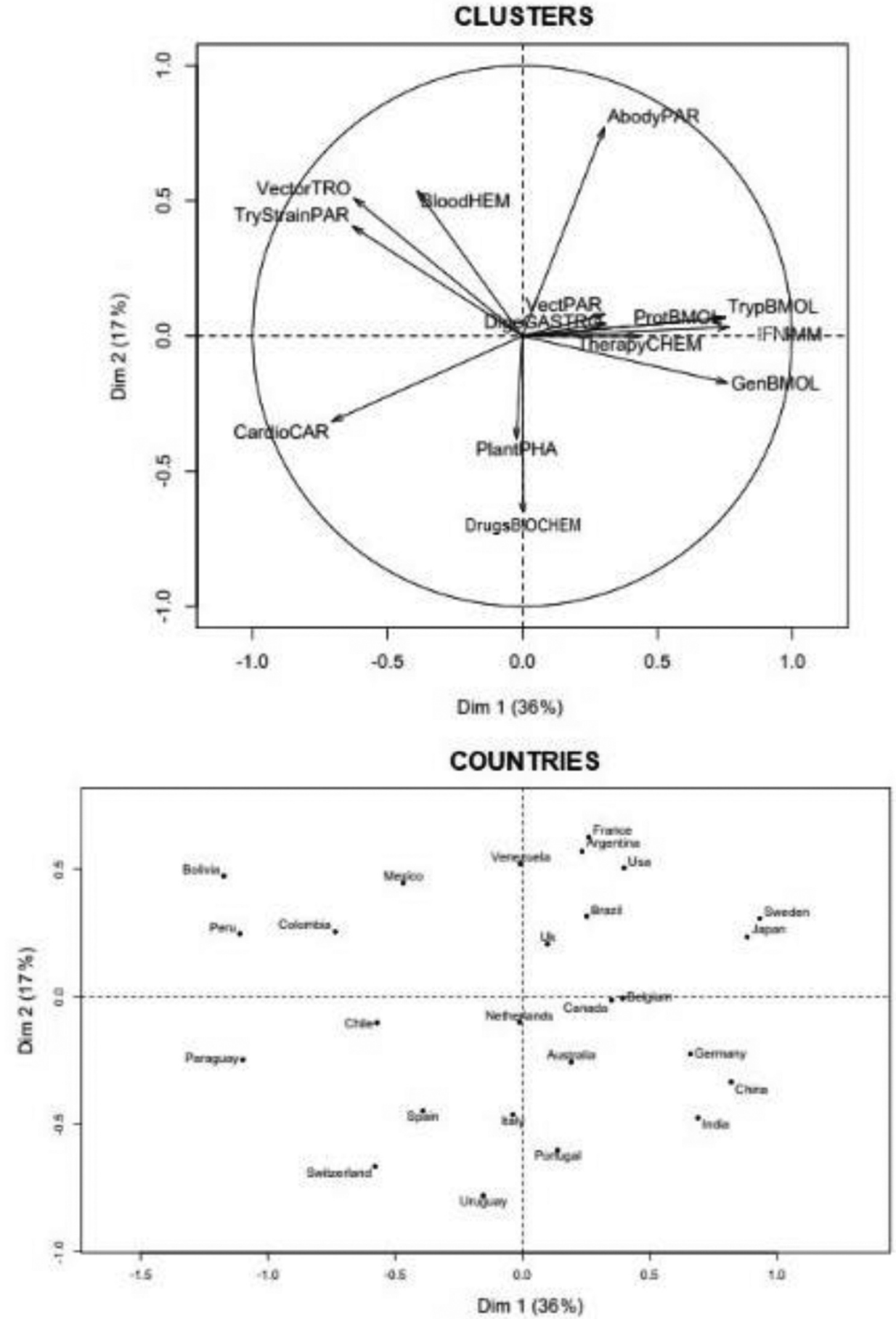

Figure 3. Distribution of countries, clusters and additional variables in the PCA. 


\section{Discussion}

We have shown that Chagas as a research problem is arranged into 14 subfields. There has been overall growth in Chagas research, led by specific clusters, such as CardioCAR, DrugsBIOCHEM or VecTRO. The only exception is AbodyPAR, which declined sharply as from the year 2000, as explained above. Most of this increase arises from the contribution of research groups located in countries without vector transmission of Chagas. The participation of these countries occurred in stages, reflecting different phenomena: the US (where the interest in the increase of vector transmission is more recent) and Spain have published research since the 1920s in the US and the 1940s in Spain) as a result of the migration of infected persons and the migration of Latin American scientists specializing in Chagas research (in particular from Brazil and Argentina). France, Sweden, the UK, and Germany started knowledge production on Chagas from the development of the T. cruzi Genome Project in the 1990s (Zingales et al 1997). More recently, China, Japan, Switzerland, Korea, Belgium, and Italy have produced articles on Chagas partly through the DNDi, created in 2003, and among all these countries researchers in the US, Spain, Switzerland, and Italy have increased their interest in the subject.

With regard to the participation of the different countries, we suggest a typology, with six profiles, organized into two broad categories: Chagas-endemic and Chagas non-endemic countries. These profiles are the result of crossing two main variables that arise in the interpretation of the analysis: 1) endemicity; 2) Chagas research traditions.

(1) Chagas-endemic countries:

(a) Countries where Chagas research traditions are weak, which focus mainly on studying the vector or the patients (Pharma, Cardio). Such are the cases of Bolivia and Mexico, which focus mainly on epidemiology and classical parasitology.

(b) Countries with strong Chagas research traditions, which study local conditions of the disease, the vector, tissues affected by the disease, and the way in which parasites interact with the organisms at molecular level, both in patients and in the laboratory. Such are the cases of Brazil and Argentina, whose topics are more "international," e.g., immunology and cardioimmunology (in association with USA and France), and to a lesser extent, modern entomology and insect control. This is a result of (a) the well-known effect of the internationalization of agendas, (b) widespread research methods, and (c) hegemonization of paradigms on how to intervene in health problems and on research in peripheral contexts, which tends to become autonomous and unrelated to local conditions (Kreimer 2019; Rodriguez-Medina et al. 2019).

(c) Countries with more recent, yet dynamic Chagas research traditions, and where the infection rate is relatively low, such as Chile and Uruguay. Research in these countries is often associated with other countries with strong pharmacological industries, such as Switzerland. Research in those countries is often driven through international initiatives with poor links with endemic countries. Those countries focused on the search for new drugs, with theoretical approaches due the absence of samples and patients.

(2) Chagas non-endemic countries.

(a) Countries that have traditionally carried out Chagas research, particularly the US and Spain, and to a lesser extent, Sweden. The high participation of the US in Chagas research has a twofold explanation. Firstly, as a result of its strong participation in all fields of research during the second half of the $20^{\text {th }}$ century. Secondly, the US's geographic proximity to Mexico, a Chagas-endemic country, has created greater concern regarding diagnostic and treatment methods, as shown by clusters one and five, and regarding vector control, due to the expansion of the vector as a result of climate change (Elith et al. 2006; Lee et al. 2013). The participation of 
Spain (and to a lesser extent, other European countries), particularly from the 2000s on, can also be explained as a consequence of strong migratory processes from Latin America, which increased considerably in recent decades. It is estimated that just over one million Latin Americans live in Europe, and many of them are carriers of the disease (Requena Méndez 2015).

(b) Countries that have joined the research dynamics in strong association with the research on the T. cruzi genome, and whose interest is not exclusively oriented to Chagas disease, but rather in understanding genetic/biological mechanisms, such as Sweden, France, Germany, and the UK.

(c) Countries that have more recently started research on these topics, related to the search for pharmacological interventions, strongly associated with the process of expansion of the disease toward non-endemic zones (Switzerland, Japan, Belgium) and the consequent increase in the interest of traditional countries (USA, Spain, Germany).

Particularly striking is the lack of large-scale continuous epidemiological studies, and social studies on the complexity of vector transmission according to lifestyle, different infection rate per sex (which is relevant, given that one of the modes of transmission is intraplacental). Also studies on the effects of migrations on the expansion of the disease and their effects on transmission. This reflects a relatively lack of interest in social and epidemiological aspects of the disease, which may be equally or more relevant to tackle Chagas as a social problem (Kreimer and Zabala 2007).

\section{Conclusions}

Our characterization of Chagas disease research offers us a conclusion that reinforces the interpretations suggested in previous qualitative studies and allows a slightly different look at the way public problems are constructed. The qualitative interpretations noted that an important part of the research on Chagas was due rather to a dynamic feature of globalized epistemic communities, than to a specific concern for solving the health problem in affected countries. The high level of interest in the parasite, instead of in patients, drugs and vectors, seems to reinforce this hypothesis. Indeed, it has been proposed that T. cruzi operates as a "model organism" (Kreimer 2019), i.e., a species that has been widely studied, usually because it is easy to maintain and breed in a laboratory setting and has certain experimental advantages (Ankeny and Leonelli 2012). This promotes research dynamics centered on the object (parasite) rather than on the broader problem generated by that object (the disease itself).

We also shown how research on vector (the insect) is the topic of less knowledge production in spite of the fact that its control (the systematic fumigation of homes) has been identified as the most successful strategy to fight against the disease (Dias and Schofield 1999; Morel 1999).

Almost a century of research has created an ever-larger stock of knowledge - as recorded in our study - yet not greater development of applied research or innovations that would translate into new drugs, new treatments, or better prevention. We can say that it was a happy story from the point of view of scientific research, but a sad story regarding the social issues.

In fact, the former can be confirmed by the new geographical distribution of knowledge: reports of most developed countries where Chagas disease is a new concern, which pointed out that there is no need of new or advanced knowledge to control the disease in their territories (Bern et al. 2019).

Qualitative studies in Latin America have suggested that the generation of knowledge with the supposed aim of addressing social problems, actually aims to develop knowledge that is considered as "modern" or "close to the frontier" and therefore "negotiable" in an international knowledge market. This hypothesis has been supported by the methodology used in the current study revealing the absence of clusters clearly oriented to clinical studies, which might be crucial to treat sick people based upon more robust knowledge. This is the case in the traditional endemic regions, namely, Latin American countries. All those interpretations were strongly confirmed by our interviews allowing us to triangulate methodologically several assertions like the utility of $T$. cruzi as a research model, the use of Chagas disease 
research to play in an international arena, the role of migrations in the spread of the disease and developed countries' focus in a research strategy that focus on diagnosis rather than on treatments.

Returning to our starting point about the relationship between scientific knowledge and public problems, we must therefore make an adjustment, insofar as knowledge is no longer only "local" to the former endemic countries, but has also become globalized. Consequently, the ways of publicly thematizing the disease also exceed the limits of each country, unlike what happened in most of the 20th century.

Indeed, old categories like "neglected disease," "disease of poverty," or "tropical disease" are no more fitted to the problem. Chagas disease is not (only) a tropical, poor, or neglected disease as we have clearly shown. In contrast, our study suggests that the confluence of new endemic zones in developed countries - where housing and sanitation conditions cannot be compared to those in Latin America - plus applied research more closely related to industrial production, may generate new drugs or treatments for Chagas disease. This production would leverage the knowledge accumulated in the various sub-fields and specialties. Since such knowledge was pioneered by the most scientifically active Latin American countries, it would be paradoxical that these countries should ultimately become clients of the potential industrial developments located in developed contexts.

\section{Notes}

1. The presence of Venezuela may be surprising. However, in a relatively limited number of articles, the existence of some highly active groups in this field in Venezuela may explain this relative "specialization".

2. Data on Chagas prevalence and the percentage of transmission types are controversial and unreliable. Uruguay currently has no vector transmission, while Chile has much lower prevalence than reported, although it does have frequent Chagas cases. The Pan American Health Organization (PAHO) is in charge of gathering this information and its reports include discrepancies. Given that Uruguay and Chile were Chagas-endemic during most of the period, we shall consider them "Chagas-endemic countries" for analytical purposes.

3. Two examples illustrate this difference. CardioCAR is the top cluster, highlighting the important role of Cardiology, which could not be inferred from its rank in the WoS subject categories of Chagas articles, which are: Parasitology; Tropical Medicine; Biochemistry \& Molecular Biology; Immunology; Infectious Diseases; Public, Environmental \& Occupational Health; Microbiology; Pharmacology \& Pharmacy; Chemistry, Medicinal; and finally Cardiology. The other example is the VecTRO cluster, which is defined by the interest in the parasite-carrying insects and ranks 4th. In contrast, Entomology is way down the WoS list in position 18, with less than two percent of the articles.

\section{Notes on contributors}

Luciano G. Levin is a researcher at the University of Río Negro and CONICET (Argentina) where he leads the postgraduate degree in STS. He works in sociology of science in particular analyzing the way in which scientific knowledge is produced and used. https://orcid.org/0000-0001-7209-805X

Pablo R. Kreimer is a sociologist and $\mathrm{PhD}$ in Science, Technology and Society. During last 30 years he carried out research on the history of scientific fields, the relationships between centers and peripheries and the production and use of knowledge, among other topics. He is a superior investigator at CONICET (National Scientific and Technical Research Council of Argentina), professor at the National University of Quilmes, and director of the STS Center at Maimónides University (Buenos Aires, Argentina). https://orcid.org/0000-0002-6737-8556

Pablo Jensen after a $\mathrm{PhD}$ on experimental condensed-matter physics, he worked for 15 years on the modeling of nanostructure growth. This led to major publications in top journals (Nature, Phys Rev Lett). He then decided to switch to the modeling of social systems. His work takes advantage of the avalanche of social data available on the Web to improve our understanding of society. https://orcid.org/0000-0001-9912-2849

\section{ORCID}

Luciano G. Levin (iD http://orcid.org/0000-0001-7209-805X

Pablo R. Kreimer iD http://orcid.org/0000-0002-6737-8556

Pablo Jensen (iD http://orcid.org/0000-0001-9912-2849 


\section{References}

Abras, A., C. Ballart, T. Llovet, C. Roig, C. Gutiérrez, S. Tebar, P. Berenguer et al.2018 Introducing automation to the molecular diagnosis of Trypanosoma cruzi infection: A comparative study of sample treatments, DNA extraction methods and real-time PCR assays. PloS One 13(4):e0195738. doi:10.1371/journal.pone.0195738.

Ankeny, A., and S. Leonelli2012 What's so special about model organisms? Studies in History and Philosophy of Science 42(2011):313-23. doi:10.1016/j.shpsa.2010.11.039.

Aslett, M., C. Aurrecoechea, M. Berriman, J. Brestelli, B P. Brunk, M. Carrington, D P. Depledge et al.2009 TriTrypDB: A functional genomic resource for the Trypanosomatidae. Nucleic Acids Research 38(suppl_1):D457-D462. doi:10.1093/nar/gkp851.

Balassa, B.1965 Trade Liberalisation and Revealed Comparative Advantage', the Manchester School of Economics and Social Studies. Vol. 33. (2). 99-123. Oxford: Blackwell Publ Ltd. doi:10.1111/j.1467-9957.1965.tb00050.x.

Becker, H. S.1963 Outsiders: Studies in the Sociology of Deviance. New York: The Free Press.

Bennett, C. et al.2018 Chagas Disease Surveillance Activities - Seven States, 2017. doi:10.15585/mmwr.mm6726a2.

Bern, C., L. A. Messenger, J. D. Whitman, and J. H. Maguire2019 Chagas disease in the United States: A public health approach. Clinical Microbiology Reviews 33(1):1-42. doi:10.1128/CMR.00023-19.

Blumer, H.1971 Social problems as collective behavior. Social Problems 18(Winter):298-306. doi:10.2307/799797.

Briceño-León, R.1990 La casa enferma. Sociología de la enfermedad de Chagas. Fondo Editorial Acta Científica Venezolana.

Buscaglia, C. A., J. C. Kissinger, and F. Aguero2015 Neglected tropical diseases in the post-genomic era, trends in genetics. 84 Theobalds Rd, London Wc1x 8rr. England: Elsevier Science London 31(10, SI):539-55. doi:10.1016/j. tig.2015.06.002.

Cambrosio, A., and P. Keating1983 The disciplinary stake: The case of chronobiology. Social Studies of Science 13 (3):323-53. doi:10.1177/030631283013003001.

Ceccarelli, S., A. Balsalobre, M. L. Susevich, M. G. Echeverria, D. E. Gorla, and G. A. Marti2015 Modelling the potential geographic distribution of triatomines infected by triatoma virus in the Southern Cone of South America. Parasites \& Vectors 8(1):153. doi:10.1186/s13071-015-0761-1.

Cerda, L., J. G. Valdivia, M. T. Valenzuela, and J. L. Venegas2008 Climate change and infectious diseases: A novel epidemiological scenario. Revista Chilena De Infectología 25(6):447-52. 10182008000600006.

Codner, D., P. Becerra, and A. Diaz2012 Blind technology transfer or technological knowledge leakage: A case study from the South. Journal of Technology Management \& Innovation 7(2):184-95. doi:10.4067/S071827242012000200015.

Conrad, P., and J. Schneider1980 Deviance and Medicalization: From Badness to Sickness. Philadelphia: Temple University Press.

Dias, J. C. P., and C. J. Schofield 1999 The evolution of chagas disease (American Trypanosomiasis) control after 90 years since carlos chagas discovery. Memorias do Instituto Oswaldo Cruz 94(suppl.1):103-21. doi:10.1590/S007402761999000700011.

Elith, J., C. H. Graham, R. P. Anderson, M. Dudik, S. Ferrier, and A. Guisan2006 Novel methods improve prediction of Species' distributions from occurrence data. Ecography (Cop) 29. doi:10.1111/j.2006.0906-7590.04596.x.

Epstein, S.1996 Impure Science AIDS, Activism, and the Politics of Knowledge. Berkeley and Los Angeles: University of California Press.

Ferpozzi, H., and L. Levin2014 Bio Bits: La influencia de las tecnologías informáticas en los procesos de producción de conocimiento en Biología Molecular. Los casos de Chagas e identificación de personas. In Perspectivas Latinoamericanas en el estudio social de la ciencia, la tecnología y la sociedad. P. Kreimer, ed. Pp. 244-58. Mexico D.F.: Siglo XXI Editores.

Gascon, J., C. Bern, and M.-J. Pinazo2010 Chagas disease in Spain, the United States and other non-endemic countries. Acta Tropica 115(1):22-27. doi:10.1016/j.actatropica.2009.07.019.

González-Alcaide, G., A. Salinas, J. M. Ramos, and W O. Dutra2018 Scientometrics analysis of research activity and collaboration patterns in chagas cardiomyopathy. PLoS Neglected Tropical Diseases 12(6):e0006602. doi:10.1371/ journal.pntd.0006602.

Gorla, D.2002 Variables ambientales registradas por sensores remotos como indicadores de la distribución geográfica de Triatoma infestans (Heteroptera: Reduviidae). Ecol Austral 12:117-127.

Grauwin, S., and P. Jensen2011 Mapping scientific institutions. Scientometrics 89(3):943-54. doi:10.1007/s11192-0110482-y.

Gusfield, J.1981 The Culture of Public Problems: Drinking-driving and the Symbolic Order. Chicago: Chicago University Press.

Hay, S. I., A. J. Tatem, A. J. Graham, S. J. Goetz, and D. J. Rogers2006 Global environmental data for mapping infectious disease distribution. Adv Parasitol 62. doi:10.1016/S0065-308X(05)62002-7.

Hilgartner, S., and C. L. Bosk1988 The rise and fall of social problems: A public arenas model. American Journal of Sociology 94(1):53-78. doi:10.1086/228951. 
Kennedy, P. G.2013 Clinical features, diagnosis, and treatment of human African trypanosomiasis (sleeping sickness). The Lancet. Neurology. England 12(2):86-194.

Kessler, M. M.1963 Bibliographic coupling between scientific articles, American documentation. Wiley Subscription Services, Inc., A Wiley Company 14(1):10-25. doi:10.1002/asi.5090140103.

Kjos, S. A., K. F. Snowden, and J. K. Olson2008 Biogeography and trypanosoma cruzi infection prevalence of chagas disease vectors in Texas, USA, Vector-Borne and Zoonotic Diseases. Mary Ann Liebert, Inc. Publishers 9(1):41-50.

Kreimer, P.2015 Co-producing social problems and scientific knowledge: Chagas disease and the dynamics of research fields in Latin America. Sociology of the Sciences Yearbook 29. Dordrecht: Springer.

Kreimer, P.2019 Science and Society in Latin America. New York: Routledge. doi:10.4324/9780429266188.

Kreimer, P., and L. Levin2013 Scientific cooperation between the European Union and Latin American Countries: Framework Programmes 6 and 7. In Research Collaborations between Europe and Latin America Mapping and Understanding Partnership J. Gaillard and R. Arvanitis, eds., Pp. 79-104. Paris: Éditions des archives contemporaines.

Kreimer, P., and H. Thomas2006 Production des connaissances dans la science périphérique: L'hypothèse CANA en Argentine. In La société des savoirs. Trompe-l'œil ou perspectives? J. B. Meyer and M. Carton eds., Pp. 14367. Paris: L'Harmattan.

Kreimer, P., and J. P. Zabala2007 Chagas disease in Argentina: Reciprocal construction of social and scientific problems. Science Technology Society 12(12):49-72. doi:10.1177/097172180601200104.

Kreimer, P., and M. Zukerfeld2014 La explotación cognitiva: Tensiones emergentes en la producción y uso social de conocimientos científicos tradicionales, informacionales y laborales. In Perspectivas latinoamericanas en el estudio social de la ciencia, la tecnología y la sociedad, P. Kreimer, H. Vessuri, L. Velho, and A. Arellano eds., Pp. 178-93. México, D.F: Siglo XXI.

Kropf, S. P.2009 Doença de Chagas, Doença do Brasil: Ciência, Saúde e Nação, 1909-1962. Río de Janeiro: Editora Fiocruz.

Le, S., J. Josse, and F. Husson2008 FactoMineR: An R package for multivariate analysis. Journal of Statistical Software UCLA CA 25(1):1-18.

Lee, B. Y., M. K. Bacon, M. E. Bottazzi, and P. J. Hotez2013 Global economic burden of chagas disease: A computational simulation model. The Lancet Infectious Diseases 13(4):342-48. doi:10.1016/S1473-3099(13)70002-1.

Levin, L., P. Jensen, P. Kreimer, and A. De2016 Does size matter? The multipolar international landscape of nanoscience. PLoS ONE 11(12):e0166914. doi:10.1371/journal.pone.0166914.

Marti, G. A., E T. González, J J. García, A R. Viguera, Diego M. A. Guérin, M G. Echeverría et al.2008 AC-ELISA and RT-PCR assays for the diagnosis of triatoma virus (TrV) in triatomines (Hemiptera: Reduviidae) species. Arch Virol 153:1427-32. doi:10.1007/s00705-008-0130-x.

Morel, C. M.1999 Chagas disease, from discovery to control - and beyond: History, myths and lessons to take home. Memorias Do Instituto Oswaldo Cruz 94(suppl. 1):3-16. doi:10.1590/s0074-02761999000700002.

Munoz, J., O. Coll, T. Juncosa, M. Vergés, M. del Pino, V. Fumado, J. Bosch et al.2009 Prevalence and vertical transmission of trypanosoma cruzi infection among pregnant Latin American Women attending 2 maternity clinics in Barcelona, Spain. Clinical Infectious Diseases: An Official Publication of the Infectious Diseases Society of America United States 48(12):1736-40. doi:10.1086/599223.

Pérez-Molina, J. A., and I. Molina2018 Chagas disease. The Lancet Elsevier 391(10115):2-94. doi:10.1016/S01406736(17)31612-4.

Requena-Méndez, A. et al.2015 Prevalence of Chagas disease in Latin-American migrants living in Europe: A systematic review and meta-analysis, PLoS neglected tropical diseases. Public Library of Science 9(2):e0003540-e0003540. doi:10.1371/journal.pntd.0003540.

Rodriguez-Medina, L., H. Ferpozzi, J. Layna, E. M. Valdez, and P. Kreimer2019 International ties at peripheral sites: Co-producing social processes and scientific knowledge in Latin America. Science as Culture 28(4):562-88. doi:10.1080/09505431.2019.1629409.

Sábato, J., and N. Botana1970 La ciencia y la tecnología en el desarrollo de América Latina. In América Latina: Ciencia y tecnología en el desarrollo de la sociedad. Amílcar Herrera, ed. Pp. 59-76. Santiago de Chile: Colección Tiempo Latinoamericano, Editorial Universitaria S.A.

Sarkar, S., S E. Strutz, D M. Frank, C. Rivaldi, B. Sissel, V. Sánchez-Cordero et al.2010 Chagas disease risk in Texas. PLoS Neglected Tropical Diseases 4(10):e836. doi:10.1371/journal.pntd.0000836.

Schijman, A. G., M. Bisio, L. Orellana, M. Sued, T. Duffy, A M. Mejia Jaramillo, C. Cura et al.2011 International study to evaluate PCR methods for detection of Trypanosoma cruzi DNA in blood samples from Chagas disease patients. PLoS Neglected Tropical Diseases 5(1):e931. doi:10.1371/journal.pntd.0000931.

Schmunis, G. A, and Z. E. Yadon2010 Chagas disease: A Latin American health problem becoming a world health problem. Acta Tropica 115(1-2):14-21. doi:10.1016/j.actatropica.2009.11.003.

Spector, M., and J. Kitsuse1977 Constructing Social Problems. Menlo Park: Cummings.

Strasen, J., T. Williams, G. Ertl, T. Zoller, A. Stich, and O. Ritter2014 Epidemiology of Chagas disease in Europe: Many calculations, little knowledge. Clinical Research in Cardiology 103(1):1-10. doi:10.1007/s00392-013-0613-y. 
Suárez, R. B. et al.2012 Situación epidemiológica y de los factores de riesgo de transmisión de Leishmania infantum en España Revista Española de Salud Pública. 86(6):555-64.

Waleckx, E., J. Suarez, B. Richards, and P. L Dorn2014 Triatoma sanguisuga blood meals and potential for Chagas disease, Louisiana, USA. Emerging Infectious Diseases 20(12):2141-43. doi:10.3201/eid2012.131576.

WHO2020 Chagas disease. https://www.who.int/en/news-room/fact-sheets/detail/chagas-disease-(americantrypanosomiasis ).

Zabala, J. P.2010 La enfermedad de Chagas en la Argentina. Bernal: Universidad Nacional de Quilmes, Investigación Científica y Políticas Sanitarias.

Zingales, B. et al.1997 The Trypanosoma cruzi genome initiative. Parasitology Today 13:16-22. 